\title{
The role of physical activity and diet in preventing cognitive decline
}

\author{
MARIANNA LIPAROTI ${ }^{1}$, GIUSEPPE MADONNA ${ }^{2}$, ROBERTA MININO ${ }^{3}$ \\ ${ }^{1,2,3}$ Department of Motor Sciences and Wellness, University of Naples "Parthenope”, Naples, ITALY
}

Published online: August 31, 2020

(Accepted for publication: August 22, 2020)

DOI:10.7752/jpes.2020.s4316

\begin{abstract}
:
In old age there is a growing incidence of cognitive deficits. Several risk factors (intrinsic and extrinsic) can affects the brain health status of elderly people. In particular, physical inactivity, sedentary behaviour and metabolic disorders related to unhealthy nutrition, could contribute to the worsening of cognitive status. Unfortunately, drug treatments have not been successful in preventing or treating cognitive decline in the elderly.Non-pharmacological but ecological strategies are needed to reduce age-related physical decline and reduce disease-related cognitive impairment in the elderly. Exercise and diet are two protective mechanisms that may reduce the cognitive decline attributed to the normal aging process and protect against changes related to neurodegenerative diseases such as Alzheimer's disease. Changes in favour of a more active lifestyle and dietary changes can potentially improve risk factors for cognitive decline. In fact, both a healthy diet and physical activity contribute to the improvement of the cardiovascular and musculoskeletal system as well as counteracting oxidative stress and reducing inflammation processes. The purpose of this study was to summarize the scientific evidence relating to the role of exercise and diet in neuroprotection and the biological mechanisms that contribute to brain health and improve the quality of life of elderly. These data are needed before more definitive conclusions can be drawn about the effectiveness of these lifestyle interventions to reduce the risk of cognitive decline. Furthermore we wanted to extrapolate recommendations regarding the most appropriate types of physical activity and diet to maintain brain health, in an effort to help clinicians and health operators to promote healthier lifestyles.

Key Words: Sport activity - Exercise - Sport nutrition - Nutrition - Diet- Cognitive impairment
\end{abstract}

\section{Introduction}

Cognitive decline play a crucial role in daily functioning of older adult and it is a serious global public health problem in rapidly growing. Epidemiological data, released by the WHO, have reported that the total number of people with cognitive dysfunctions is expected to reach 82 million in 2030 and 152 million in 2050(Organization, 2019). In lifespan the human brain, undergoes age-related atrophy phenomena of the frontal, parietal and temporal regions (Jernigan et al., 2001). Unfortunately, these brain changes affect the cognitive abilities, causing the decline of memory and executive functions, the inability to perform tasks simultaneously that require a change of attention, difficulties in daily life activities, slower response times, reduction of information processing speed and reduction of inhibitory control (Glisky, 2007).

Cognitive decline is due to the combination of intrinsic and extrinsic risk factors (Organization, 2019). Intrinsic risk factors are related to the subject's characteristics, which include immutable biological features such as age, gender, race and genetic factors. Instead the modifiable risk factors mainly concerned people's lifestyle and include the physical inactivity or unhealthy diet.

Clinical and epidemiological data strongly suggest that poor dietary practices and insufficient levels of exercise, lifestyles typical of our modern society, increase the riskto develop cognitive deficits and many neurodegenerative diseases, such as Alzheimer's disease (AD)(Fratiglioni, Paillard-Borg, \& Winblad, 2004).

Unfortunately, drug treatments have not been successful in preventing or treating cognitive decline in older adult, this highlights the need to use non-pharmaceutical approaches such as physical activity (PA) and healthy nutrition, to predict and prevent any risk factors or delay the manifestation of cognitive symptoms related to AD. Metabolic chronic diseases are closely related to cognitive disorders, significantly contributing to arterial obstruction through atherosclerosis processes, and thus favoring ischemic brain damage. In recent decades, many researchers have focused their attention on the mechanisms underlying cognitive decline, highlighting the close relationship between neurodegeneration and nutrition. They suggested that since nutritional factors can influence brain health by acting on both metabolic and vascular risk factors, as well as inflammation and oxidative stress, it is clear that there is a link between nutrition and cognitive impairment. Pathological processes leading to 
neuronal loss begin their activity long time before clinical symptoms occur. A current challenge is to understand how eating habits, during the whole life of a person, may modify the risk and the severity of cognitive decline. Also the sedentary behaviour and physical inactivity might induce the cognitive decline, instead the active lifestyle positively affect the cognitive process although the biological mechanisms which result in such effect are only poorly understood. Colcombe and Kramer (Colcombe \& Kramer, 2003; Kramer \& Colcombe, 2018) conducted the meta-analysis studies, to highlight that PA has effects on the cognitive function of non-demented older adults. The authors observed a significant effect of aerobic exercise training on cognitive functions and neuronal plasticity that are maintained throughout the lifespan. Studies about the association between PA and brain health, have found that more PA early in life is associated with greater brain volume later in life(Erickson et al., 2009, 2010). These studies revealed that people who practice high levels of aerobic activity had larger hippocampal volumes and exhibited better spatial memory performance associated with hippocampal volume. These results suggest that aerobic PA may offer a protective effect on the brain by modifying AD-related changes in brain structure.

There are several studies that have highlighted how specific nutrients or dietary patterns and specific PA or multimodal activities contribute to the improvement of vascularization, energy metabolism and oxidative stress processes, with a consequent positive impact on the maintenance of cognitive functions.

Here, we will discuss the clinical and experimental evidence showing how physical activity (PA) and diet may affect brain health and prevent neurodegenerative diseases.

The aim of this review is to describe the evidence for the beneficial effects of PA and diet as well as promoting PA and diet as an ecological approaches useful for improving people's quality of life. In addition, another aim was also to extrapolate recommendations regarding the type of PA and diet most appropriate for maintaining brain health.

\section{Material \& methods}

Procedure

A systematic searches were conducted in the databases PUBMED and SCOPUS. In order to perform this research, we used a set of Keywords reported in Figure 1. In this figure the key point is represented by the AND block, which merges the other peripheral blocks, which contains the keywords and their synonyms separated by an OR condition. In this way, the search is made through the intersection of at least one word for each block. For the bibliographic research, the works published from 2015 to 2020 were selected. After a preliminary search the following exclusion criteria were applied: 1) exclusion of review articles; 2) exclusion of all studies that do not include healthy elderly people as target population; 3) exclusion of all studies written in a language other than English.

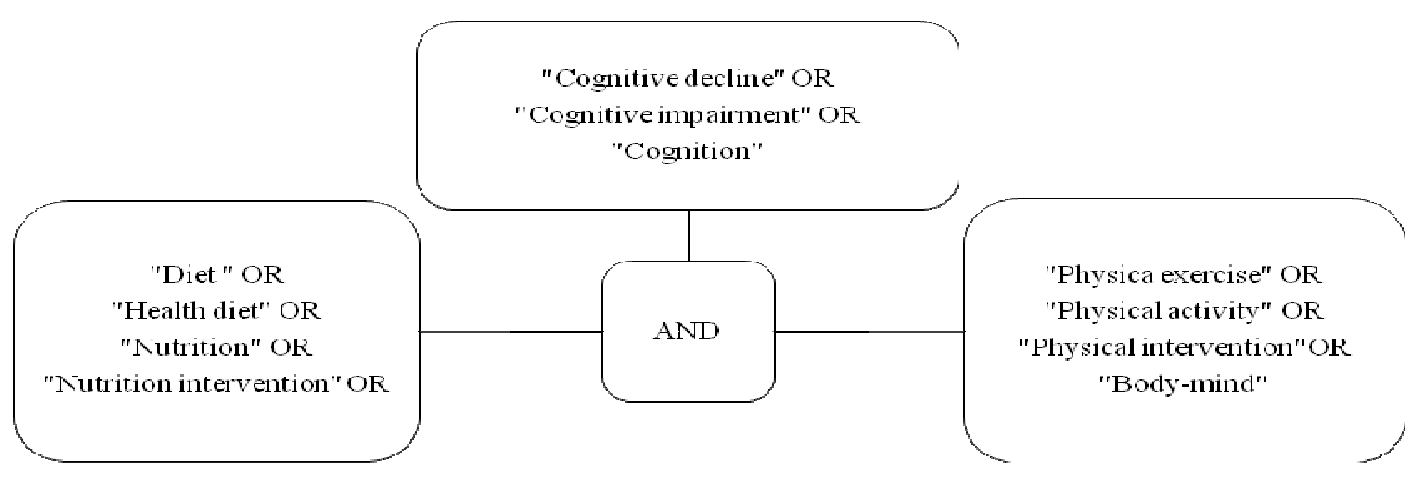

Fig.1Set of Keywords

\section{Results}

After a preliminary search, 362 articles have been found about the effects of physical exercise on cognitive decline, while 220 articles about effects of healthy diet and cognitive decline we found. After the application of the exclusion criteria, 9 articles concerning the effect of PA on the brain for the prevention of cognitive decline were included in the study.

Furthermore 8 articles concerning the effect of healthy diet for the prevention of cognitive decline were included in the study. Table 1 provides an overview of the selected articles of the effects of physical activity for the maintenance of cognitive functions. In addition in Table 2 are reported the effects of healthy diet on brain functions. 
Tab. 1 Summary of articles on the effects of physical activity for the maintenance of cognitive functions.

\begin{tabular}{|c|c|c|c|c|}
\hline Authors (years) & Participants (Age) & Type of activity & Duration & Outcames \\
\hline (Sun et al., 2015) & $150(68.3)$ & Tai Chi & $\begin{array}{l}2 \text { weeks } \times 6 \text { months } \\
(60 \text { minutes })\end{array}$ & $\begin{array}{l}\text { Frontal Assessment Battery } \\
\text { (FAB); Mini-Mental State } \\
\text { Examination (MMSE) }\end{array}$ \\
\hline (Sink et al., 2015) & 1635 (70 to 89$)$ & $\begin{array}{l}\text { Moderate- } \\
\text { intensity physical } \\
\text { activity program }\end{array}$ & 24 months & $\begin{array}{l}\text { Digit Symbol Coding (DSC); } \\
\text { Hopkins Verbal Learning Test }\end{array}$ \\
\hline $\begin{array}{l}\text { (Sáez de Asteasu et } \\
\text { al., 2019) }\end{array}$ & $370(75)$ & $\begin{array}{l}\text { Multicomponent } \\
\text { exercise training } \\
\text { programme }\end{array}$ & $\begin{array}{l}5-7 \text { consecutive } \\
\text { days (two } \\
\text { sessions/day) }\end{array}$ & $\begin{array}{l}\text { Mini- } \\
\text { Mental State Examination } \\
\text { (MMSE) }\end{array}$ \\
\hline $\begin{array}{l}\text { (Izquierdo et al., } \\
\text { 2019) }\end{array}$ & $370(75)$ & $\begin{array}{l}\text { Moderate- } \\
\text { intensity } \\
\text { resistance, } \\
\text { balance, and } \\
\text { walking exercises }\end{array}$ & 2 daily sessions & $\begin{array}{l}\text { Mini- } \\
\text { Mental State Examination } \\
\text { (MMSE); Mood } \\
\text { Status; Questionnaire for } \\
\text { quality of life (QoL); } \\
\text { Confusion Assessment Method. }\end{array}$ \\
\hline $\begin{array}{l}\text { (Liu-Ambrose et } \\
\text { al., 2015) }\end{array}$ & $70(74)$ & $\begin{array}{l}\text { Aerobic exercise } \\
\text { training }\end{array}$ & $\begin{array}{l}6 \text { months of thrice- } \\
\text { weekly }\end{array}$ & $\begin{array}{l}\text { Global executive } \\
\text { function;Stroop Test; } \\
\text { Alzheimer's Disease } \\
\text { Cooperative Study-Activities } \\
\text { of Daily }\end{array}$ \\
\hline $\begin{array}{l}\text { (Imaoka et al., } \\
\text { 2019) }\end{array}$ & $67(75.2)$ & $\begin{array}{l}\text { Multicomponent } \\
\text { exercise training } \\
\text { programme }\end{array}$ & 45 min $\times 3$ months & $\begin{array}{l}\text { Living (ADCS-ADL) scale; } \\
\text { Mini-Mental State } \\
\text { Examination (MMSE); Trail } \\
\text { making test (TMT) }\end{array}$ \\
\hline $\begin{array}{l}\text { (Hwang et al., } \\
\text { 2016) }\end{array}$ & $456(60)$ & Tai Chi & $\begin{array}{l}60 \text { min } \times 6 \text { months } \\
\text { (every day) }\end{array}$ & $\begin{array}{l}\text { Mini-Mental State } \\
\text { Examination (MMSE); } \\
\text { Geriatric Depression } \\
\text { Scale }\end{array}$ \\
\hline $\begin{array}{l}\text { (Greblo Jurakic, } \\
\text { Krizanic, Sarabon, } \\
\text { \& Markovic, 2017) }\end{array}$ & $28(66-78)$ & $\begin{array}{l}\text { Resistance } \\
\text { training; Pilates }\end{array}$ & $\begin{array}{l}\text { Pilates } 1 \mathrm{~h} \times 8 \\
\text { weeks; Resistance } \\
\text { training } 30 \mathrm{~min} \times 8\end{array}$ & $\begin{array}{l}\text { Montreal Cognitive } \\
\text { Assessment (MoCA) }\end{array}$ \\
\hline $\begin{array}{l}\text { (Gothe, Kramer, \& } \\
\text { McAuley, 2017) }\end{array}$ & $118(62)$ & Yoga & $\begin{array}{l}\text { weeks } \\
3 \text { times } \times 8 \text { weeks }\end{array}$ & $\begin{array}{l}\text { Attention } \\
\text { Network Test (ANT) }\end{array}$ \\
\hline
\end{tabular}

Tab. 2 Summary of articles on the effects of Diet for the maintenance of cognitive functions.

\begin{tabular}{|c|c|c|c|c|}
\hline Authors (years) & Participants (Age) & $\begin{array}{l}\text { Type of nutrition } \\
\text { or diet }\end{array}$ & Duration & Outcames \\
\hline $\begin{array}{l}\text { (Calapai et al., } \\
\text { 2017) }\end{array}$ & $57(55-75)$ & Cognigrape & 12weeks & $\begin{array}{l}\text { Mini-Mental State } \\
\text { Examination (MMSE), Beck } \\
\text { Depression Inventory (BDI); } \\
\text { Hamilton Anxiety Rating } \\
\text { Scale (HARS); Repeatable } \\
\text { Battery for the Assessment of } \\
\text { Neuropsychological Status } \\
\text { (RBANS) evaluations }\end{array}$ \\
\hline $\begin{array}{l}\text { (Danthiir et al., } \\
\text { 2018) }\end{array}$ & $194(65-90)$ & $\begin{array}{l}\text { Docosahexaenoic } \\
\text { acid (DHA) }\end{array}$ & 18 months & A battery of cognitive tests \\
\hline $\begin{array}{l}\text { (Kean et al., } \\
2015)\end{array}$ & $37(67)$ & $\begin{array}{l}\text { Flavanone-rich } \\
\text { orange juice }\end{array}$ & 8 weeks & $\begin{array}{l}\text { Executive function; Episodic } \\
\text { memory test }\end{array}$ \\
\hline $\begin{array}{l}\text { (Külzow et al., } \\
\text { 2016) }\end{array}$ & $22(50-75)$ & Omega-3 & 26 weeks & $\begin{array}{l}\text { Visuospatial memory; } \\
\text { Standard neuropsychological } \\
\text { test }\end{array}$ \\
\hline $\begin{array}{l}\text { (Mastroiacovo et } \\
\text { al., 2015) }\end{array}$ & $90(61-85)$ & $\begin{array}{l}\text { Flavanol } \\
\text { consumption }\end{array}$ & 8 weeks & A battery of cognitive tests \\
\hline $\begin{array}{l}\text { (Nilsson, Salo, } \\
\text { Plaza, \& Björck, } \\
\text { 2017) }\end{array}$ & $20(50-70)$ & $\begin{array}{l}\text { Berry beverage } \\
\text { with polyphenols }\end{array}$ & 5 week & A battery of cognitive tests \\
\hline $\begin{array}{l}\text { (Scott, } \\
\text { Rasmussen, } \\
\text { Chen, \& Johnson, } \\
\text { 2017) }\end{array}$ & $20(63)$ & Avocado & 6 months & A battery of cognitive tests \\
\hline $\begin{array}{l}\text { (Valls-Pedret et } \\
\text { al., 2015) }\end{array}$ & $447(60)$ & Mediterranean diet & 5 years & A battery of cognitive tests \\
\hline
\end{tabular}




\section{Dicussion}

In this study we illustrated an overview of the effects of healthy diet and PA on brain functions in order to highlight the beneficial effects on cognitive performance in healthy elderly individuals.

Although with some exception, the results of cross-sectional, prospective and retrospective epidemiological studies, support a relationship between the cognitive activity of older adults and PA. In literature, it is known that correct lifestyles and constant exercise are related to better performance on cognitive tasks such as greater executive control, better controlled attention, an improvement of spatial skills and the speed of information processing in older adults.

Movement has played a crucial role in the adaptability of the organism to the environment. Therefore, it is plausible to assume the presence of a retrograde flow of information with feedback functions to the central nervous system. The details of such a signalling system are still incomplete, but experimental observations suggest two fundamental mechanisms. Evidence indicates that events associated with energy balance can play a role in nervous functions. Brain metabolic responses to acute PA seems to extend beyond the regions specifically associated with skeletal motor, sensory, and cardiovascular autonomic control(Ide \& Secher, 2000). Lactate taken up from skeletal muscle seems to act as an intercellular energy shuttle within the brain during highintensity exercise. Exercise limits the use of glucose by the muscle to assure sufficient amounts for the increased brain metabolic needs.

However, there is also clear evidence for effects of PA on nervous functions that are only indirectly dependent, or independent on energy metabolism. In the hippocampus, exercise has been found to significantly increase the levels of a mitochondrial protein that promotes the adenosine triphosphate (ATP) synthesis. Vaynman et al. (Vaynman, Ying, Wu, \& Gomez-Pinilla, 2006)proposed a model in which the presence of mitochondrial protein at the pre-synaptic and post-synaptic membranes could allow neuronal mitochondria to limit oxidative stress (OS), increase ATP production and modulate calcium levels. These results suggest the presence of fundamental mechanisms by which exercise affects key elements of energy metabolism that modulate substrates of synaptic plasticity underlying learning and memory.

From the evidence reported in this brief review, it may be deduced that multiple physiological mechanisms induced by PA may contribute to the conservation or improvement of brain functions and health. In the present study, the collection of articles highlighted a small effect of mind-body exercise on overall cognitive function. These evidences of the effect of mind-body exercise on overall cognition are congruent with previous reviews examining the effectiveness of Tai Chi, Pilates and Yoga on overall cognitive function. When participating in mind-body exercises, participants are committed to remembering movement patterns and sequences and this has benefits on the frontal lobe and regulation of executive function(Gothe et al., 2017; Hwang et al., 2016; Sun et al., 2015).

Therefore the physical exercise seems to have neuroprotective effects and reducing the risk of pathological processes and favouring phenomena of plasticity of the brain through neurogenesis and synaptogenesis, the effect of exercise is essential for better general brain health and for the recovery of cerebellar skills (Lardone et al., 2018; Montuori et al., 2019; Sorrentino et al., 2019). Specifically, moderate-intensity exercise (aerobic or resistance) (Colcombe \& Kramer, 2003; Kramer \& Colcombe, 2018; Liu-Ambrose et al., 2010)seems to be effective not only in promoting a state of physical health (Davide Di Palma, Raiola, \& Tafuri, 2016; Napolitano, Ascione, \& Di Palma, 2017; Napolitano, Perciavalle, \& Ascione, 2017; D di Palma \& Tafuri, 2016; Raiola, Lipoma, \& Tafuri, 2015)butalso to promote brain health.

In the literature, various evidences are available on the effects of food components on brain health andin the previous section we reported some evidence.

Many evidences demonstrate effect of nutrients and/or diet on neuronal functions in particular high amount of cholesterol in neural membranes can regulate the level of $\beta$-amyloid $(A \beta)$ in the brain (Simons et al., 1998). Moreover, cholesterol-enriched high-fat diet seems to promote A $\beta$ deposition(Refolo et al., 2000). Many nutrients such as policosanol, have a direct control on cholesterol levels and a hypocholesterolemic activity (Menéndez et al., 2001).

An alternative approach to regard the relationship between food and cognitive decline is the evidence that neurodegenerative disorders such as $\mathrm{AD}$ may be delayed by cerebrovascular health caring low-salt diet and/or high dose folate associated with other strategies able to control hypertension could help in reducing risk for vascular events and AD (Luchsinger et al., 2005). Diet rich of anti-oxidant compound also could have relevant effect in decreasing risk of dementia due to the high contents of polynsatured fatty acids (PUFA) in neuronal membranes, while flavonors from fruits, cocoa beans and Ginko biloba was shown to reduce learning and memory impairment in rodents (Pu et al., 2007). The effect of diet can be appreciated when this in enriched with products such as alpha lipoic acid (in spinach, broccoli, peas and yeast) and Vitamin E (in vegetable oils, nuts) which improves memory deficits and promotes neurological performances in human (KONTUSH \& SCHEKATOLINA, 2004). The findings described in Table 2 show that nutrition intervention has a positive impact on cognitive functioning of healthy older people. From this collection of papers, it appears that several nutrients exhibit a beneficial effect on brain health, but the interaction of specific foods and nutrients, especially in the MedDiet(Valls-Pedret et al., 2015), appears to have a fairly positive effect on cognitive performance in healthy elderly individuals. In fact, the MedDiet seems to be a nutritional model for healthy eating habits as it 
contains all the necessary nutrients: monounsaturated fatty acids, polyunsaturated fatty acids, antioxidants, vitamins and minerals. Furthermore, the combination of these nutrients positively influences pathological neurodegenerative processes such as oxidative stress, neuroinflammation, insulin resistance and reduced cerebral blood flow. In contrast, research implies that dietary patterns high in fat and sugar, with a high intake of meat / poultry or eggs, have negative and detrimental effects on cognitive functioning in old age.

\section{Physical activity recommendations}

Research studies on the relationship between brain health and physical activity have made it possible to develop guidelines for the promotion of health in the elderly. The World Health Organization (Organization, 2019; WHO, 2010), recognizing physical activity as a possible modifiable factor useful for promoting health in general, has disclosed the main guidelines for all healthy adults over 65 age, to improve both fitness cardiorespiratory and muscle, that brain functions. The elderly should do at least 150 minutes of moderateintensity aerobic physical activity during the week or at least 75 minutes of vigorous-intensity aerobic physical activity during the week or an equivalent combination of moderate and vigorous intensity activity. To encourage additional health benefits, older adults should increase their moderate intensity aerobic exercise to 300 minutes per week or engage in 150 minutes of vigorous aerobic physical activity per week or equivalent combination of moderate and vigorous intensity activities.

The elderly, with mobility deficits, should carry out physical activity 3 or more days a week, to improve their motor ability and prevent the falls. In addition, in order to enhance muscle activity, elderly should carry out activities involving the main muscle groups 2 or more days a week. An improvement in cognitive performance, in particular executive functions, it has been shown following a participation in long-term resistance exercise programs (Liu-Ambrose et al., 2010).

\section{Diet recommendations}

Emerging results from preclinical and clinical studies show that in addition to lifestyle changes and a constancy in physical activity, diet can also be an important modifiable factor useful for the prevention of cognitive decline (Barnard et al., 2014). From these results, are emerged several recommendations, which include minimizing the intake of trans fats and saturated fats, dairy products and increased consumptions of vegetables, legumes (beans, peas, and lentils), fruits and whole grains. In addition, various dietary models are suggested in order to reduce or prevent the typical pathological signs of cognitive decline, including the ketogenic diet (Rusek, Pluta, Ułamek-Kozioł, \& Czuczwar, 2019), the Mediterranean diet (Titova et al., 2013) and dietary approaches to reduce calorie consumption and improve the cardiovascular system and brain health.

\section{Conclusions}

PA and diet may act to modify risk factors related to the onset of cognitive decline. Both PA and diet represent a non-pharmacological but ecological approaches capable to act as useful protective mechanisms to reduce the age-related cognitive impairment in the elderly. However, further research seems to be needed to clarify how PA and diet affect brain functions or act directly on the structure and function of the brain for better prevention of brain disorders.

\section{Conflicts of interest}

The authors declare no conflict of interest.

\section{References}

Barnard, N. D., Bush, A. I., Ceccarelli, A., Cooper, J., de Jager, C. A., Erickson, K. I., ... Lucey, B. (2014). Dietary and lifestyle guidelines for the prevention of Alzheimer's disease. Neurobiology of Aging, 35, S74-S78.

Calapai, G., Bonina, F., Bonina, A., Rizza, L., Mannucci, C., Arcoraci, V., ... Alecci, U. (2017). A randomized, double-blinded, clinical trial on effects of a Vitis vinifera extract on cognitive function in healthy older adults. Frontiers in Pharmacology, 8(OCT), 1-8. https://doi.org/10.3389/fphar.2017.00776

Colcombe, S., \& Kramer, A. F. (2003). Fitness effects on the cognitive function of older adults: a meta-analytic study. Psychological Science, 14(2), 125-130.

Danthiir, V., Hosking, D. E., Nettelbeck, T., Vincent, A. D., Wilson, C., O’Callaghan, N., ... Wittert, G. A. (2018). An 18-mo randomized, double-blind, placebo-controlled trial of DHA-rich fish oil to prevent agerelated cognitive decline in cognitively normal older adults. American Journal of Clinical Nutrition, 107(5), 754-762. https://doi.org/10.1093/ajcn/nqx077

Di Palma, Davide, Raiola, G., \& Tafuri, D. (2016). Disability and Sport Management: a systematic review of the literature. Journal of Physical Education and Sport, 16(3), 785.

Erickson, K. I., Prakash, R. S., Voss, M. W., Chaddock, L., Hu, L., Morris, K. S., ... Kramer, A. F. (2009). Aerobic fitness is associated with hippocampal volume in elderly humans. Hippocampus, 19(10), 1030 1039. 
Erickson, K. I., Raji, C. A., Lopez, O. L., Becker, J. T., Rosano, C., Newman, A. B., ... Kuller, L. H. (2010). Physical activity predicts gray matter volume in late adulthood: the Cardiovascular Health Study. Neurology, 75(16), 1415-1422.

Fratiglioni, L., Paillard-Borg, S., \& Winblad, B. (2004). An active and socially integrated lifestyle in late life might protect against dementia. The Lancet Neurology, 3(6), 343-353.

Glisky, E. L. (2007). Changes in cognitive function in human aging. Brain Aging: Models, Methods, and Mechanisms, 3-20.

Gothe, N. P., Kramer, A. F., \& McAuley, E. (2017). Hatha Yoga Practice Improves Attention and Processing Speed in Older Adults: Results from an 8-Week Randomized Control Trial. Journal of Alternative and Complementary Medicine, 23(1), 35-40. https://doi.org/10.1089/acm.2016.0185

Greblo Jurakic, Z., Krizanic, V., Sarabon, N., \& Markovic, G. (2017). Effects of feedback-based balance and core resistance training vs. Pilates training on cognitive functions in older women with mild cognitive impairment: a pilot randomized controlled trial. Aging Clinical and Experimental Research, 29(6), 12951298. https://doi.org/10.1007/s40520-017-0740-9

Hwang, H. F., Chen, S. J., Lee-Hsieh, J., Chien, D. K., Chen, C. Y., \& Lin, M. R. (2016). Effects of HomeBased Tai Chi and Lower Extremity Training and Self-Practice on Falls and Functional Outcomes in Older Fallers from the Emergency Department - A Randomized Controlled Trial. Journal of the American Geriatrics Society, 64(3), 518-525. https://doi.org/10.1111/jgs.13952

Ide, K., \& Secher, N. H. (2000). Cerebral blood flow and metabolism during exercise. Progress in Neurobiology, 61(4), 397-414.

Imaoka, M., Nakao, H., Nakamura, M., Tazaki, F., Maebuchi, M., Ibuki, M., \& Takeda, M. (2019). Effect of multicomponent exercise and nutrition support on the cognitive function of older adults: A randomized controlled trial. Clinical Interventions in Aging, 14, 2145-2153. https://doi.org/10.2147/CIA.S229034

Izquierdo, M., Martínez-Velilla, N., Casas-Herrero, A., Zambom-Ferraresi, F., Sáez De Asteasu, M. L., Lucia, A., ... Rodríguez-Mañas, L. (2019). Effect of Exercise Intervention on Functional Decline in Very Elderly Patients During Acute Hospitalization: A Randomized Clinical Trial. JAMA Internal Medicine, 179(1), 28-36. https://doi.org/10.1001/jamainternmed.2018.4869

Jernigan, T. L., Archibald, S. L., Fennema-Notestine, C., Gamst, A. C., Stout, J. C., Bonner, J., \& Hesselink, J. R. (2001). Effects of age on tissues and regions of the cerebrum and cerebellum. Neurobiology of Aging, 22(4), 581-594.

Kean, R. J., Lamport, D. J., Dodd, G. F., Freeman, J. E., Williams, C. M., Ellis, J. A., ... Spencer, J. P. E. (2015). Chronic consumption of flavanone-rich orange juice is associated with cognitive benefits: an 8-wk, randomized, double-blind, placebo-controlled trial in healthy older adults. The American Journal of Clinical Nutrition, 101(3), 506-514.

KONTUSH, A., \& SCHEKATOLINA, S. (2004). Vitamin E in neurodegenerative disorders: Alzheimer's disease. Annals of the New York Academy of Sciences, 1031(1), 249-262.

Kramer, A. F., \& Colcombe, S. (2018). Fitness effects on the cognitive function of older adults: a meta-analytic study - revisited. Perspectives on Psychological Science, 13(2), 213-217.

Külzow, N., Witte, A. V., Kerti, L., Grittner, U., Schuchardt, J. P., Hahn, A., \& Flöel, A. (2016). Impact of Omega-3 Fatty Acid Supplementation on Memory Functions in Healthy Older Adults. Journal of Alzheimer's Disease, 51(3), 713-725. https://doi.org/10.3233/JAD-150886

Lardone, A., Liparoti, M., Sorrentino, P., Rucco, R., Jacini, F., Polverino, A., ... Sorriso, A. (2018). Mindfulness Meditation Is Related to Long-Lasting Changes in Hippocampal Functional Topology during Resting State: A Magnetoencephalography Study. Neural Plasticity, 2018.

Liu-Ambrose, T., Davis, J., Best, J. R., Eng, J. J., Lee, P. E., Jacova, C., ... Robin Hsiung, G.-Y. (2015). O5-0404: Vascular cognitive impairment and aerobic exercise: A 6-month randomized controlled trial. Alzheimer's \& Dementia, 11(7S_Part_7), P323-P324. https://doi.org/10.1016/j.jalz.2015.07.466

Liu-Ambrose, T., Nagamatsu, L. S., Graf, P., Beattie, B. L., Ashe, M. C., \& Handy, T. C. (2010). Resistance training and executive functions: a 12-month randomized controlled trial. Archives of Internal Medicine, 170(2), 170-178.

Luchsinger, J. A., Reitz, C., Honig, L. S., Tang, M.-X., Shea, S., \& Mayeux, R. (2005). Aggregation of vascular risk factors and risk of incident Alzheimer disease. Neurology, 65(4), 545-551.

Mastroiacovo, D., Kwik-Uribe, C., Grassi, D., Necozione, S., Raffaele, A., Pistacchio, L., ... Desideri, G. (2015). Cocoa flavanol consumption improves cognitive function, blood pressure control, and metabolic profile in elderly subjects: The cocoa, cognition, and aging (CoCoA) study-A randomized controlled trial. American Journal of Clinical Nutrition, 101(3), 538-548. https://doi.org/10.3945/ajcn.114.092189

Menéndez, R., Amor, A. M., Rodeiro, I., González, R. M., González, P. C., Alfonso, J. L., \& Más, R. (2001). Policosanol modulates HMG-CoA reductase activity in cultured fibroblasts. Archives of Medical Research, $32(1), 8-12$.

Montuori, S., D’Aurizio, G., Foti, F., Liparoti, M., Lardone, A., Pesoli, M., ... Sorrentino, P. (2019). Executive functioning profiles in elite volleyball athletes: Preliminary results by a sport-specific task switching protocol. Human Movement Science, 63(July 2018), 73-81. https://doi.org/10.1016/j.humov.2018.11.011 
Napolitano, S., Ascione, A., \& Di Palma, D. (2017). Analysis of posture and its impact on performance in women's water polo. Open Access J Sci, 1(3), 91-95.

Napolitano, S., Perciavalle, V., \& Ascione, A. (2017). Pilot study in youth volleyball: Video analysis as a didactic tool. Giornale Italiano Di Educazione Alla Salute, Sport e Didattica Inclusiva, 1(2).

Nilsson, A., Salo, I., Plaza, M., \& Björck, I. (2017). Effects of a mixed berry beverage on cognitive functions and cardiometabolic risk markers; A randomized cross-over study in healthy older adults. PLoS ONE, 12(11), 1-22. https://doi.org/10.1371/journal.pone.0188173

Organization, W. H. (2019). Risk reduction of cognitive decline and dementia: WHO guidelines. In Risk reduction of cognitive decline and dementia: WHO guidelines (p. 401).

Palma, D di, \& Tafuri, D. (2016). Special needs and inclusion in sport management: a specific literature review. Sport Science, 9(Suppl. 2), 24-31.

Pu, F., Mishima, K., Irie, K., Motohashi, K., Tanaka, Y., Orito, K., ... Iwasaki, K. (2007). Neuroprotective effects of quercetin and rutin on spatial memory impairment in an 8-arm radial maze task and neuronal death induced by repeated cerebral ischemia in rats. Journal of Pharmacological Sciences, 707310004.

Raiola, G., Lipoma, M., \& Tafuri, D. (2015). Postural control in young soccer players: differences between the cognitive approach and ecological-dynamic one.

Refolo, L. M., Pappolla, M. A., Malester, B., LaFrancois, J., Bryant-Thomas, T., Wang, R., ... Duff, K. (2000). Hypercholesterolemia accelerates the Alzheimer's amyloid pathology in a transgenic mouse model. Neurobiology of Disease, 7(4), 321-331.

Rusek, M., Pluta, R., Ułamek-Kozioł, M., \& Czuczwar, S. J. (2019). Ketogenic diet in Alzheimer's disease. International Journal of Molecular Sciences, 20(16), 3892.

Sáez de Asteasu, M. L., Martínez-Velilla, N., Zambom-Ferraresi, F., Casas-Herrero, Á., Cadore, E. L., RamirezVelez, R., \& Izquierdo, M. (2019). Inter-individual variability in response to exercise intervention or usual care in hospitalized older adults. Journal of Cachexia, Sarcopenia and Muscle, 10(6), 1266-1275. https://doi.org/10.1002/jcsm.12481

Scott, T. M., Rasmussen, H. M., Chen, O., \& Johnson, E. J. (2017). Avocado consumption increases macular pigment density in older adults: a randomized, controlled trial. Nutrients, 9(9), 919.

Simons, M., Keller, P., De Strooper, B., Beyreuther, K., Dotti, C. G., \& Simons, K. (1998). Cholesterol depletion inhibits the generation of $\beta$-amyloid in hippocampal neurons. Proceedings of the National Academy of Sciences, 95(11), 6460-6464.

Sink, K. M., Espeland, M. A., Castro, C. M., Church, T., Cohen, R., Dodson, J. A., .. Vaz Fragoso, C. A. (2015). Effect of a 24-month physical activity intervention vs health education on cognitive outcomes in sedentary older adults: The LIFE randomized trial. JAMA - Journal of the American Medical Association, 314(8), 781-790. https://doi.org/10.1001/jama.2015.9617

Sorrentino, P., Lardone, A., Pesoli, M., Liparoti, M., Montuori, S., Curcio, G., ... Foti, F. (2019). The development of spatial memory analyzed by means of ecological walking task. Frontiers in Psychology, 10(MAR). https://doi.org/10.3389/fpsyg.2019.00728

Sun, J., Kanagawa, K., Sasaki, J., Ooki, S., Xu, H., \& Wang, L. (2015). Tai chi improves cognitive and physical function in the elderly: A randomized controlled trial. Journal of Physical Therapy Science, 27(5), 14671471. https://doi.org/10.1589/jpts.27.1467

Titova, O. E., Ax, E., Brooks, S. J., Sjögren, P., Cederholm, T., Kilander, L., ... Åhlström, H. (2013). Mediterranean diet habits in older individuals: associations with cognitive functioning and brain volumes. Experimental Gerontology, 48(12), 1443-1448.

Valls-Pedret, C., Sala-Vila, A., Serra-Mir, M., Corella, D., de la Torre, R., \& Martinez-Gonzalez, M. A. (2015). Mediterranean diet and age-related cognitive decline: a randomized clinical trial. JAMA Intern Med. 2015; 175 (7): 1094-103.

Vaynman, S., Ying, Z., Wu, A., \& Gomez-Pinilla, F. (2006). Coupling energy metabolism with a mechanism to support brain-derived neurotrophic factor-mediated synaptic plasticity. Neuroscience, 139(4), 1221-1234.

WHO, W. H. O. (2010). Global recommendations on physical activity for health. Geneva World Heal Organ, 60. 